\title{
Diskursus Sumber Daya Manusia dan Perubahan dalam Organisasi menurut Pemikiran Frederick Herzberg
}

\author{
Dasmadi \\ Fakultas Ekonomi, Universitas Boyolali \\ E-mail: dasmadiboyolali82@gmail.com
}

\begin{abstract}
Article Info
Article History

Received: 2021-11-10

Revised: 2021-11-28

Published: 2021-12-06

Keywords:

Change;

Organization;

Herzberg;

Human Resource.

Abstract

This article is a theoretical-reflective construction of thought regarding the existence of human resources in a corporation. As a necessary reality, changes in corporations occur with various background events and certain arguments. One of the changes in the corporation is an event or events related to the existence of human resources. This reflective article builds on the thinking of the American psychologist Frederick Herzberg, Herzberg's theory of motivation is based on the principle that job satisfaction and dissatisfaction have a relationship with each other. Certain factors can intersect with job satisfaction while other factors relate to job dissatisfaction. This work factor was mapped by Herzberg into two major themes, namely the Cleanliness Factor and the Motivational Factor. The motivational theory as Herzberg thought would be used to analyze Dahlan Iskan's leadership model as a leader, as well as he as part of the configuration of human resources in a BUMN corporation, PT. PLN (Persero). The results of the study show that the factors related to motivational factors are owned by Dahlan Iskan, and he uses it to manage the hygiene factor. In this study, the elementary and spectacular changes in the body of PLN, under the command of Dahlan Iskan became a model for a company leader who was smart in concocting motivational factors and cleanliness factors into energy for corporate change that invited public respect.
\end{abstract}

\begin{tabular}{l}
\hline Artikel Info \\
\hline Sejarah Artikel \\
Diterima: $2021-11-10$ \\
Direvisi: 2021-11-28 \\
Dipublikasi: 2021-12-06
\end{tabular}

Kata kunci:

Perubahan; Organisasi; Herzberg; $S D M$.

\begin{abstract}
Abstrak
Artikel ini merupakan konstruksi pemikiran teoretis-reflektif mengenai eksistensi sumber daya manusia dalam sebuah korporasi. Sebagai sebuah realitas yang niscaya, perubahan dalam korporasi terjadi dengan berbagai latar kejadian dan argumentasi tertentu. Salah satu perubahan dalam korporasi adalah kejadian atau peristiwa yang berkaitan dengan eksistensi sumber daya manusia. Artikel reflektif ini mengambil pijakan pada pemikiran seorang psikolog Amerika Frederick Herzberg, Teori Motivasi Herzberg berdasar pada kaidah bahwa kepuasan kerja dan ketidakpuasan memiliki relasi satu sama lain. Faktor - faktor tertentu bisa bersinggungan dengan kepuasan kerja sedangkan faktor lain berkaitan dengan ketidakpuasan kerja. Faktor pekerjaan ini dipetakan oleh Herzberg ke dalam dua tema besar, yakni Faktor Kebersihan dan Faktor Motivasi.Teori motivasi sebagaimana pemikiran Herzberg akan digunakan untuk menganalisis model kepemipinan Dahlan Iskan sebagai seorang pemimpin, sekaligus dia sebagai bagian dari konfigurasi sumber daya manusia dalam korporasi BUMN, PT PLN (Persero). Hasil penelitian menujukkan bahwa faktor - faktor yang berkaitan dengan faktor motivasi dimiliki oleh Dahlan Iskan, dan dia gunakan untuk untuk mengelola faktor kebersihan. Dalam kajian ini perubahan yang elementer dan spektakuer di tubuh PLN, dibawah komando Dahlan Iskan menjadi model pemimpin perusahaan yang pintar meramu faktor motivasi dan faktor kebersihan menjadi energi perubahan korporasi yang mengundang respek publik.
\end{abstract}

\section{PENDAHULUAN}

Realitas perubahan merupakan hal niscaya dalam sebuah korporasi, sekaligus sebagai indikator betapa dinamika dan proses aktif organisasi sedang terjadi. Hanya saja eksistensi perubahan selalu menelurkan dua buah kenyataan yang dapat kita anggap sebagai kenyataan yang saling berpapasan. Pergeseran kepemimpinan melahirkan kenyataan baru bagi korporasi yang bersifat positif, atau malah berkebalikannya, dimana sebuah perubahan melahirkan kenyataan negatif. Kedua kenyataan buah dari perubahan itu membutuhkan pengelolaan yang pas, sehingga mampu merubah arah vector dari negatif ke positif, atau seandainya vektor, eksesnya tidak terlalu bersifat merusak atau bahkan menghancurkan eksistensi suatu korporasi, sejarah mengenai perubahan sebenarnya sejarah yang diperoleh insan secara langsung dari Yang Maha Kuasa, Tuhan seru 
sekalian alam. Dalam terminologi agama Islam misalnya, jalan nalar perubahan menurut agama itu yang mengatakan Tuhan tidak akan mengubah nasib umat manusia jika mereka tidak berusaha untuk mengubahnya sendiri. Dalam konteks itu menjadi jelas betapa dalam diskursus spiritual pun, terdapat seruan tentang perubahan. Ini artinya ada semacam argumentasi teologis dalam peristiwa perubahan. Digayutkan dengan pesan - pesan teologis diatas, maka perubahan dapat dipandang sebagai sebuah kebutuhan di dalam kehidupan yang mesti dipenuhi. Disisi lain, ada juga semangat bahwa hiduplah mengalir seperti air ? Frasa itu sebenarnya merupakan metafora yang sebenarnya bukan untuk menegasi munculnya sebuah perubahan dalam kurun waktu, akan tetapi bahwa hidup yang dinamis wajib dilalui dengan memegang erat prinsip tertentu, lalu dijalani dengan tenang layaknya air yang mengalir dengan tenang dan yakin pada tujuannya. Dalam hal itu mesti ada sebuah realitas dinamika perubahan yang arahnya adalah positif. Prinsip - prinsip tertentu tadi menjadi signifikan agar hidup insan manusia tidak dipermainkan oleh sebuah ketidakpastian layaknya berada di ruang hampa, nir gravitasi dan udara. Tidak mungkin orang kemudian menjadi statis, mandeg, akan menemui jalan kehidupan yang membuat nyaman dan bahagia. Manusia sesti merespon pesan adikodrati untuk berbenah dan berubah.

Kini, dalam kenyataan kehidupan masyarakat modern-kontemporer, organisasi atau korporasi yang dibuat, baik organisasi bisnis, politik, organisasi birokrasi dan lain sebagainya, kian bergerak dinamis dan meniscayakan perubahan dari waktu ke waktu. Terjadinya perubahan itu bisa dipicu dan dipacu oleh factor-faktor internal maupun eksternal sebuah korporasi /organisasi. Faktor yang bersumber dari internal korporasi misalnya adalah soal sumber daya manusia atau man power yang sudah tidak aktif-produktif. Sementara itu faktor eksternal misalnya adalah menurunnya daya saing dipasar akibat sebuah korporasi belum memanfaatkan teknologi baru, semakin sempitnya ruang pemasaran, model atau postur kebijakan politik negara dan faktor lain sebagainya.

Kemudian, manakala korporasi telah menancapkan komitmen untuk tetap ada dan bermakan, maka sistesis perubahan dari dalam yang dasarnya adalah kesadaran internal pengelola / manajemen menjadi tonggak pijakan yang baik. Bermula dari asumsi tersebut, artikel ini akan membahas bagaimana sebuah kekuatan energi dari dalam (energi endogen yang berasal dari sumber daya korporasi) dapat posisikan untuk mengelola terjadinya kemungkinan perubahan dalam korporasi/organisasi tersebut.

A. Pemikiran Herzberg

Pemikiran Herzberg di kenal sebagai Teori Dua Faktor atau Teori Motivasi dan Kebersihan, juga sering disebut teori faktor ganda yang. Ia adalah seorang psikolog dan ilmuwan perilaku Amerika pada tahun 1959. Teori ini berada dalam lingkup proposisi bahwa dua jenis faktor dapat ditemukan di tempat kerja, yang dapat menciptakan kepuasan kerja, memotivasi karyawan dan yang lainnya yang menyebabkan ketidakpuasan dan mengurangi moral dan dorongan karyawan untuk bekerja, Herzberg berpendapat bahwa kepuasan kerja dan ketidakpuasan bukanlah ujung kutub dari metrik yang sama tetapi berbeda metrik independen dan berbeda. Dia menyatakan bahwa kebalikan dari kepuasan bukanlah ketidakpuasan tetapi kurangnya kepuasan dan kebalikan dari ketidakpuasan bukanlah kepuasan tetapi kurangnya ketidakpuasan.

Frederick Herzberg menerbitkan hasil pengamatannya tentang berbagai aspek yang ada di lingkungan kerja yang memiliki dampak signifikan pada tingkat motivasi karyawan dalam buku 'Motivasi untuk Bekerja' pada tahun 1959, dalam bukunya itu, Herzberg mengelompokan hal -hal yang menjadi faktor kepuasan dan faktor ketidakpuasan, yaitu sebagai berikut:

Tabel 1. Pengelompokan Faktor Kepuasan dan Ketidakpuasan

\begin{tabular}{l|l}
\multicolumn{1}{c}{ Faktor Kepuasan } & \multicolumn{1}{c}{ Faktor Ketidakpuasan } \\
\hline Pengakuan & Kondisi kerja \\
\hline Pencapaian & Gaji \\
\hline Pertumbuhan & Kebijakan perusahaan \\
\hline Tanggung Jawab & Hubungan dengan kolega \\
\hline Peluang untuk maju & Pengawasan \\
\hline Merasa penting & Hubungan dengan atasan
\end{tabular}

B. Faktor Kepuasan - Motivasi

Faktor-faktor motivasi adalah yang berhubungan dengan metrik kepuasan dan merupakan faktor-faktor yang secara positif bertindak untuk dan memastikan kepuasan atau motivasi selama rentang waktu tertentu. Faktor-faktor ini tidak berurusan dengan metrik ketidakpuasan. Faktor motivasi adalah 
faktor-faktor yang memungkinkan peningkatan kinerja karyawan. Faktor-faktor ini lebih bersifat intrinsik sedangkan faktor kebersihan kurang lebih bersifat ekstrinsik.

Dia menetapkan 6 faktor penting sebagai faktor Motivasi dan dalam urutan kepentingannya, mereka adalah Prestasi, Pengakuan, Sifat pekerjaan, Tanggung jawab, Kemajuan dan Pertumbuhan. Seorang karyawan jika ia dikenali oleh katakanlah karyawan tahun ini atas kerja keras yang telah ia lakukan, maka karyawan itu sendiri akan merasa puas dan akan termotivasi.

Lembaga penghargaan semacam itu setiap tahun akan membuat karyawan lain berjuang untuk itu dan akan memotivasi mereka juga. Ada banyak faktor yang dapat memotivasi karyawan seperti yang diidentifikasi dalam teori ini. Faktor-faktor yang biasanya diamati yang secara positif mempengaruhi kepuasan yang disebut Motivator meliputi sifat kerja, pengakuan terhadap pencapaian seseorang, peluang kemajuan, tanggung jawab, rasa penting, dan dimasukkan dalam proses pengambilan keputusan.

\section{Faktor Ketidakpuasan - Kebersihan}

Faktor kebersihan mengacu pada faktorfaktor pekerjaan yang tidak secara positif menjamin kepuasan atau motivasi dalam jangka waktu yang lama, tetapi merupakan faktor-faktor tersebut ketika absen menyebabkan ketidakpuasan dan penurunan moral, faktor-faktor ini bukan aktor positif yang memungkinkan peningkatan motivasi, tetapi merupakan alasan positif mengapa karyawan tidak boleh tidak puas dengan pekerjaannya. Faktor-faktor ini juga dikenal sebagai Faktor Ketidakpuasan atau Pemeliharaan karena fakta bahwa ia berurusan dengan metrik ketidakpuasan.

\section{Tingkatan Manajemen Perubahan Dalam Korporasi}

Terminologi Management of change atau manajemen perubahan dapat dipahami sebagai upaya yang sifatnya upaya sistematis dan struktural yang digunakan untuk menerapkan sarana, sumber daya, serta knowledge agar sebuah perubahan dapat di meminimalisir dampak negatifnya, pengelolaan perubahan menjadi sebuah tantangan tersendiri bagi seorang pemimpin yang dapat mencari solusi bagi perbaikan korporasi. Tentu saja tantangan itu wajib didekati dengan kerja kerja yang sifatnya metodis, artinya dilakukan dnegan cara yang lebih terorganisir melalui metode tata kelola yang benar.

Dalam praktik pengelolaan perubahan, Harischandra (2007), mengidentifikasi beberapa jenis perubahan dalam suatu perusahaan dan organisasi berdasarkan sifatnya, yaitu:

1. Smooth incremental change, merupakan perubahan yang akan terjadi dan berjalan secara lambat, sistematis, dan bisa diprediksi. Peristiwanya menca-kup rentetan perubahan dan cenderung konstan.

2. Bumpy incremental change, adalah perubahan yang mempunyai periode cenderung tenang dan sesekali terjadi percepatan perubahan yang dipicu perubahan lingkungan organisasi. Pemicu yang dimaksud bisa berasal dari internal perusahaan seperti adanya tuntutan atau perubahan pola kerja.

3. Discontinuous change, adalah perubahan yang diawali dengan adanya pergeseran dengan cepat terhadap struktur, budaya, dan strategi secara bersamaan.

Didalam praktik pengelolaan perubahan organisasi / perusahaan terdapat tingkatan atau strata perubahan yang terjadi dalam proses tersebut. Jenjang ini memberikan informasi kepada kita pada level mana sebuah perubahan berpengaruh pada kinerja sebuah organisasi. Secara sederhana strata itu dapat dirumuskan sebagai berikut: (1) Perubahan Individu. Pada level ini ada kesadaran alamiah betpa pada dasarnya setiap individu pasti akan selalu mengalami perubahan. Untuk itu peranan manajer sangat diperlukan untuk mengatur arah perubahan individu agar kongruen dengan orietasi korporasi. Dalam hal ini ada hal utama yang perlu diperhatikan yakni pendekatan humanis oleh pemimpin agar energi perubahan pada level individu itu menjadi produktif nir gejolak, sekecil apapun, (2) Perubahan Organisasi. Level berikutnya adalah perubahan organisasi. Pada perubahan level ini, mungkin tidak menyangkut organisasi secara keseluruhan, namun mungkin saja struktur / departemen tertentu yang berubah. Perubahan secara parsial pada divisi tertentu. (3) Perubahan pada level korporasi. Pada level ini secara organisatoris holistik pada sebuah korporasi. Nyaris seratus persen perusahaan mengalami perubahan tata kelola, sehingga muncul model kinerja dan performa perusahaan yang baru. Umumnya perubahan 
ini di inisiasi oleh pemimpin tertinggi perusahaan. Perubahan itu diciptakan oleh pemimpin perusahaan dan juga dikelola olehnya dengan tujuan meningkatkan performa yang lebih andal dari korporasi tersebut.

Menghadapi dinamika perubahan sosial pada lingkungan bisnis global dan regional sekalipun, perusahaan harus menganalisis segala perubahan yang terjadi dengan cermat untuk meminimalisasi dampak negative yang mungkin memengaruhi eksistensi korporasi. Fakta ini menurut Mc Calman dalam Paton (1992) menjelaskan bahwa tuntutan perubahan berasal dari perubahan eksternal yang sedang dihadapi oleh kebanyakan organisasi modern dewasa ini di dunia internasional diantaranya akan timbul sebuah pasar global yang lebih luas, yang menjadi lebih "kecil" karena meningkatnya unsur persaingan dari luar negeri. Disisi lain Rodriguez et.all (2016) mengkaji betapa perubahan organisasi tertentu justru terjadi setelah privatisasi, dalam risetnya di temukan bahwa variabel pendukung perubahan adalah kebebasan bagi manajemen dalam berkreasi, terlebih bagi perubahan yang lebih besar setelah dilakukan privatisasi.

\section{METODE PENELITIAN}

Kajian ini menggunakan pendekatan kualitatif dengan metode deskriptif yaitu dengan cara mengumpulkan, menganalisis, membuat gambaran dan mempersingkat segala kondisi dan situasi dari data yang telah terkumpul. Kajian ini mencoba melihat realitas atau permasalahan dengan teori motivasi Frederick Herzberg. Penelitian ini merupakan penelitian kualitatif reflektif dengan pendekatan studi Pustaka. Data data diambil dari berbagai sumber seperti buku, jurnal,dan lainnya. Analisis data yang dilakukan untuk menjawab permasalahan yang ada pada penelitian ini adalah reduksi data, yang selanjutnya dianalisis berdasarkan teori teori yang dipilih dalam penelitian ini dan disajikan dalam bentuk narasi ilmiah.

\section{HASIL DAN PEMBAHASAN}

A. Orientasi Sentrifugal dan Faktor Kepuasan Heizberg

Jika kita amati, dinamika korporasi merupakan realitas yang tidak bisa dihindari. Dinamika yang memiliki kemungkinan menghasilkan berbagai perubahan merupakan hal yang niscaya terjadi. Realitas keniscayaan perubahan ini telah banyak dilukiskan oleh korporasi-korporasi yang memang seolah dalam sejarah "dikehendaki" untuk menampilkan perubahan yang hebat. Ilustrasi dalam naskah ini tentang perubahan organisasi menjadi salah satu catatan monumental dalam tata kelola perusahaan. Ilustrasinya adalah kepemipinan Dahlan Iskan di PLN dan juga ketika di kementerian BUMN.

Semenjak ditunjuk untuk memimpin PLN, Dahlan dengan cepat membuat beberapa model gebrakan dengan cara mengidentifikasi potensi masalah di tubuh PLN. Di perusahaan yang memproduksi arus listrik itu, Dahlan mengidentifikasi adanya lima permasalahan utama dan besar yang harus ditumbangkan lekas - lekas. Masalah nomor 1(satu) adalah krisis listrik. Nomor 2 (dua) panjangnya daftar tunggu pemasangan sambungan bagi pelanggan baru PLN. Masalah nomor 3 (tiga) adalah soal banyaknya gangguan teknis pada trafo induk maupun pada tiang-tiang distribusi listrik. Masalah nomor 4 (empat) yaitu adanya gangguan feeder (penyulang) dengan intensitas yang sangat tinggi, dan masalah nomor 5 (lima) tentang inefisiensi yang akut dalam tubuh perusahaan arus listrik pelat merah tersebut.

Penampakan kepemimpinan khas Dahlan Iskan yang paling menonjol adalah mengenai gaya manajemennya. Dalam interval waktu dua tahun menjabat Direktur Utama PLN, pada 17 Oktober 2011, Dahlan Iskan lantas ditunjuk oleh Presiden SBY (Susilo Bambang Yudhoyono kala itu) untuk mengisi kursi sebagai Menteri BUMN (Badan Usaha Milik Negara). Sama dengan pada saat menahkodai PLN, begitu menjadi Menteri BUMN, Dahlan menetapkan mission of three di kementeriannya. Misi pertama adalah bahwa BUMN harus bisa didayagunakan sebagai alat untuk memperkuat ketahanan nasional. Semua industri strategis wajib masuk grup ini, apalagi BUMN yang memang bergerak dibidang pangan. Kedua, BUMN harus bisa menampilkan performanya dengan berfungsi sebagai powerfull engine of economic growth nasional. Ketiga, BUMN harus bisa menjadi salah satu instrumen menumbuhkan kebanggaan nasional.

Contoh kasus perubahan didalam korporasi sebagaimana tertulis diatas merupakan resultante dari kekuatan seorang pempimpin yang energi pemikirannya bersifat sentrifugal. Artinya vektor gaya berpikir ketika mendapati realitas perusahaan dengan performa buruk, 
di arahkan ke luar yakni pada organisasi bisnis tersebut. Energi bukan diarahkan kedalam, yang dalam hal ini berorientasi pada diri sendiri, melainkan ke segenap aspek organisasi. Energi pemimpin yang berorientasi ke dalam diri, umumnya akan menampilkan perilaku yang arahnya untuk kepentingan personal pemimpin tersebut. Seorang pemimpin tidak menempatkan kepentingan perusahaan atau organisasi sebagai hal utama, karena mengikuti anasir - anasir buruk dengan diri sebagai pusat, lalu mengambil keuntungan personal dengan hebatnya.

Energi sentrifugal yang dimanifestasikan pada organisasi bisnis jasa semacam PLN, sebenarnya akan dipancarkan meluas lagi kepada masyarakat. Dalam hal ini terutama adalah para pelanggan dan shared holder serta stake holder. Dahlan Iskan sebagai pemimpin perusahaan dapat dipandang telah berhasil menampilkan kepemimpinan sentrifugal karena arahnya adalah kepuasan pihak pengguna layanan. Dan didalam perusahaan pun, gaya sentrufugal dihadirkan dengan orientasi kesejahteraan pegawai, bukan kesejahteraan diri sebagai bos suatu korporasi.

Andai di análisis dengan konsep pemikiran Herzberg, maka sebagai pemimpin dia berada dalam kolom Faktor Kepuasan yang mengidentifikasi hal - hal elementer seperti Pengakuan, Pencapaian, Pertumbuhan, Tanggung Jawab, Peluang untuk maju dan Merasa penting. Kita sebagai masyarakat bisa mendeteksi hal itu dengan cara menghubungkan perilaku kepe- mimpinannya dengan landasan logika teoretis menurut Herzberg.

\section{B. Kepemimpinan Dahlan Iskan Perspektif Motivasi Herzberg}

Analisis perilaku memimpin terhadap gaya Dahlan Iskan sebagai nahkoda PLN dan Kementerian BUMN cukup menarik dilakukan dari sudut pandang teori motivasi Herzberg. Terdapat ekspresi perilaku yang merupakan manifestasi dari permikiran - pemikiran teoretis Herzberg. Dalam kenyataanya, Dahlan telah mencoba dua sisi diametral pemikiran Herzberg mengenai motivasi bekerja yang terbagai menjadi faktor kepuasan dan faktor ketidakpuasan. Elemen - elemen yang masuk dalam unit kategorial itu diramunya menjadi perilaku kepemimpinan sebagaimana Dahlan tampilkan ketika menjadi petinggi PLN dan
Kementerian BUMN. Dari teori itu dapat dianalisis betapa Dahlan menampilkan :

1) Dimensi Pengaruh Ideal

Dahlan dapat digambarkan mampu membuat kondisi dimana anak buah atau pengikutnya mengagumi, respect dan sangat percaya serta tingkat kepatuhan tinggi. Dia adalah sosok yang mempunyai visi, misi dan target yang sangat - sangat masuk akal dan jelas. Dalam konteks ini misalnya, saat PLN dibawahnya ditargetkan pembangunan Pembangkit Listrik Tenaga Surya di 100 pulau di Indonesia hingga tahun 2011. Kemudian pada saat menjadi Menteri BUMN Dahlan Iskan dengan tidak segan membuka gerbang tol ketika terjadi kemacetan panjang karena faktor internal Jasa Marga, yakni karena belum semua gerbang tol dibuka.

2) Dimensi Inspirasi Ideal

Konstruksi berpikir dalam dimensi ini adalah manakala seorang pemimpin sanggup mengartikulasikan pengharapan yang jelas terhadap kemampuan dan prestasi bawahan, sanggup memanifestasikan komitmennya terhadap semua tujuan organisasi, dan mampu memicu dan memacu spirit tim dalam korporasi. Caranya adalah menemukan teknik untuk mengembangkan entusiasme dan optimisme seluruh insan sumberdaya manusia di lingkungan korporasi itu. Dalam konteks itu Dahlan Iskan ketika menjabat sebagai dirut PLN adalah melakukan supervisi dan pengawasan dengan turun lapangan ke lebih dari 400 kabupaten/kota di Indonesia dalam jangka waktu setahun saja. Dimensi inspirasi ideal Dahlan dalam bidang anggaran adalah mengusahakan transparansi dan akuntabilitas keuangan dengan membuka pintu bagi KPK (Komisi Pemberantasan Korupsi) dan Badan Pemeriksa Keuangan (BPK) untuk dapat mengakses langsung data keuangan PT PLN (persero) tersebut.

3) Dimensi Stimulasi Ideal

Pada perspektif ini seorang pemimpin harus sanggup memunculkan pemikiran segar, ide-ide yang kontemporer, pemecah masalah yang andal bagi problematika perusahaan dan juga para pegawai di bawahnya, serta mencari terobosan baru dalam berbagai departemen dilingkup perusahaan atau korporasi tersebut. Dalam 
diskursus perbaikan performa dan kinerja, Dahlan saat menjabat dirut PLN memutar otak untuk mencari pengganti bahan bakar pembangkit listrik manakala pasokan gas alam berhenti sama sekali. Agar krisis listrik bisa diatasi dan pasokan arus listrik untuk Jawa Bali bisa dipertahankan. Dahlan beralih ke bahan bakar minyak, daripada harus memadamkan Jakarta sebagai pusat ekonomi dan pemerintahan. Meski defisit anggaran sebesar Rp 37 triliun lebih, Langkah itu diambil agar eksistensi PLN sebagai penyedia listrik tetap terjaga dan menjaga marwah korporasi. Memang selalu ada pilihan dalam membuat keputusan dan juga konsekuensinya masing-masing.

\section{SIMPULAN DAN SARAN}

\section{A. Simpulan}

Perubahan dalam organisasi merupakan sebuah keniscayaan, sehingga yang diperlukan adalah pengelolaan atau manajemen perubahan itu sendiri. Secara alamiah akan ada sumber - sumber perubahan, meski dalam skala sekecil apapun. Perubahan dapat dipicu antara lain oleh elemen - elemen yang ada dalam tubuh suatu organisasi atau lembaga. Salah satu elemen itu adalah sumber daya manusia, dimana padanya tersimpan energi potensial yang berpeluang untuk melakukan perubahan. Disisi lain, setiap insan tentu mempunyai motif untuk melakukan sesuatu, yang dalam sudut pandang Herzberg, Dahlan telah menampilkan kepemimpinan berbasis kepuasan dan ketidakpuasan. Ilustrasi kasus dalam tulisan ini adalah salah satu cermin tentang sosok pemimpin perusahaan yang berhasil memadupadankan dua faktor Herzberg, yang ahirnya menjadi energi perubahan bagi organisasi yang monumental. Dahlan pada dasarnya telah berhasil menancapkan tonggak transformasional untuk sebuah tata kelola korporasi yang baik.

\section{B. Saran}

Riset ini sesungguhnya baru berada dalam level teoretis, karena berbasis data skunder, sehingga masih perlu penelitian lanjutan untuk menemukan kemungkinan nilai-nilai lain dalam diri sosok Dahlan Iskan. Penelitian lanjutan yang diperlukan misalnya lebih bersifat empiris sehingga bisa menemukenali lebih lanjut kebaikan yang tersembunyi. Penelitian dengan pendekatan fenomenologi.
DAFTAR RUJUKAN

Hakim, A. N., Dewi, D. A., \& Furnamasari, Y. F. (2021). Peran Guru dalam Membangun Karakter dan Moral Siswa Melalui Pendidikan Kewarganegaraan. JIIP - Jurnal Ilmiah Ilmu Pendidikan,4(8), 748-752. https://doi.org/10.54371/jiip.v4i8.341

Harischandra, Hans. 2007. Pengaruh Manajemen Perubahan Terhadap Budaya Organisasi dan Gaya Kepemimpinan Manager di PT. Alfa Retailindo Tbk. Jurnal Manajemen, Vol.3, No.1.

Kasali, Rhenald, 2005, Change, PT Gramedia Pustaka Utama, Jakarta

Robbins, Stephen P., 2005, Organizational Behavior, Concept Contropversies and Applications, Prentice Hall Inc. USA. Terjemahan. Jakarta: P.T. Indeks Kelompok Gramedia.

Rodriguez, Gloria Cuevas; Villegas,Jaime Guerrero; \&Cabrera,Ramón Valle , (2016),"Corporate governance changes, firm strategy and compensation mechanisms in a private- zation

Turkoguz, S. (2012). Learn to teach chemistry using visual media tools. Journal Chemistry Education Research and Practise.13(4), 401-409.

Uno, H. B. (2017). Teori Motivasi dan Pengukuran nya. Yogyakarta: Bumi Aksara. 